\title{
CHANGES IN VELOCITY OF FISHER GLACIER, EAST ANTARCTICA USING PIXEL TRACKING METHOD
}

\author{
S. D. Jawak ${ }^{1,2}$, A. Upadhya ${ }^{3, *}$, P. H. Pandit ${ }^{4}$, A. J. Luis ${ }^{2}$ \\ ${ }^{1}$ Svalbard Integrated Arctic Earth Observing System (SIOS), SIOS Knowledge Centre, University Centre in Svalbard (UNIS), P.O. \\ Box 156, N-9171, Longyearbyen, Svalbard, Norway; shridhar.jawak@gmail.com \\ ${ }^{2}$ Earth System Science Organization - National Centre for Antarctic and Ocean Research, Ministry of Earth Sciences, Government of \\ India, Headland Sada, Vasco-da-Gama, Goa 403804, India; alvluis@ ncaor.gov.in \\ ${ }^{3}$ Institute of Environment Education and Research, Bharati Vidyapeeth University, Pune- 411403, Maharashtra, India; \\ adithiru095@protonmail.com \\ ${ }^{4}$ Department of Natural Resources, TERI University, New Delhi- 110 070, India; sh.prashantpandit@gmail.com
}

Commission V, SS: Atmosphere, Ocean, Weather and Climate

KEY WORDS: Glacier velocity, image matching, Antarctica, COSI-corr

\begin{abstract}
:
Glacier movement is a crucial factor for assessing cryospheric climate change. Traditional methods of field surveys for studying glacier movement and velocity are often not possible owing to inaccessibility and harsh terrains. Furthermore, as it is not feasible to physically monitor and survey many glaciers around the globe, these traditional methods are limited in their global coverage. Remote sensing is an ideal tool to study such phenomena on a global scale. Optical remote sensing employs techniques such as feature tracking and pixel tracking, whereas, microwave remote sensing uses intensity tracking, speckle tracking, Interferometric SAR and Differential InSAR (DInSAR). This study focuses on estimation of glacier velocity and its seasonal variations using the imagematching technique for optical images for the Fisher glacier, a tributary glacier of the Amery ice shelf in Antarctica. The tool used in this study is the COSI-Corr module embedded in ENVI which provides the velocity in both azimuth and range resolution. The principle of estimating velocity using this tool is pixel tracking wherein similar pixels on two images are tracked where one is the master image and the other is a slave. This technique correlates the master and slave images over a time period and generates three outputs: displacements in the East-West and North-South directions and signal-to-noise ratio (SNR) image. Landsat 8 image pairs were used for cross correlation over a time span of four years spanning 2013-2017. With a resolution of 15m, the panchromatic band (Band 8) was the ideal choice for pixel tracking as the resolution of other bands is coarser. The initial window size for correlation was 64 while the final window size was 16. The resolution of the displacement images produced is dependent on the value assigned for the step size, which was set to 8 . The resultant velocity was derived using the result of the two displacement images. The SNR image was used to remove all the pixels from the velocity output having the value of SNR less than 0.9 , in order to reduce the effect of noise. The annual velocity of the Fisher glacier was estimated to be around 600 to 650 myr $^{-1}$ near the tongue where it merges with the Amery Ice Shelf, which was reduced to $150 \mathrm{myr}^{-1}$ as it recedes. The resultant velocity images have a resolution of $120 \mathrm{~m}$. The seasonal variation in velocity for the year 2013-2014 is $1.8 \mathrm{myr}^{-1}$, while in the succeeding year 2014-2015 it subdued to $1.7 \mathrm{myr}^{-1}$. The seasonal variation for the year 2015-2016 was estimated to be $7.9 \mathrm{myr}^{-1}$. The seasonal variation for 2016- $2017 \mathrm{was}^{17.4} \mathrm{myr}^{-1}$.
\end{abstract}

\section{INTRODUCTION}

Nearly global repeat coverage of the Earth's surface by optical satellite sensors provides global-scale mapping and monitoring of glacier flow for monitoring glacier physics, glacier-related climate change and glacier hazard management. There are many ways to map and monitor the velocity of a glacier (Jawak et al., 2018; Pandit et al., 2018; Jawak et al. 2017). Most of the studies are performed using SAR and optical data. The methodologies used to study velocity through SAR include Synthetic aperture radar interferometry InSAR (Goldstein et al., 1993), Differential Synthetic Aperture Radar Interferometry-DInSAR (Lanari et al., 2007), SAR offset tracking (Strozzi et al., 2002), and feature tracking which allows the tracking of much smaller surface features with a precision in yearly velocity of a few $\mathrm{cm}$ per year. Feature tracking (using optical or radar imagery) and InSAR can provide patially distributed and multi-temporal velocity fields of horizontal glacier surface displacement (Watson and Quincey, 2015). Moreover, this method is ideally suited for resolving areas of fast glacier movement. Feature tracking is a method involves estimation of displacement between two images where the first one is called a reference image and the second image is called a search image (Heid and Kääb, 2012, Strozzi et al., 2002). First, a window $\Omega \mathrm{r}$ is chosen in the reference image centered around pixel $(i, j)$. Next a window of same size is extracted from the search image but translated by $(\mathrm{p}, \mathrm{q})$ pixels within a specified search window $\Omega \mathrm{s}$ and compared to $\Omega \mathrm{r}$ using a function of similarity. This operation is repeated for different values of $(\mathrm{p}, \mathrm{q})$ and the position of the maximum of similarity, interpolated to a fraction of a pixel, is a measure of the displacement (Dehecq et al., 2016).

Until the 1980s, image matching was done by manually inspecting the images and identifying the same objects in the images from two different time periods. This work was very time consuming and there were no possibilities for obtaining sub-pixel measurements. Scambos et al., (1992) was the first to perform image matching automatically on glaciers. They used image matching algorithms based on normalized crosscorrelation (NCC). They found that doing this automatically was not just less time consuming, but it was also more accurate than doing it manually. Image matching methods can be either area-based or feature-based. Area-based methods operate directly on image quantities like brightness or phase. Featurebased methods on the other hand match features that are 
extracted from the images in a pre-processing step. Such features can be crevasses, rocks or other differences in digital numbers (DN). The size of the windows to be correlated is important in glaciological studies. The window size has to be large enough to ensure that texture and not noise is matched. For small window sizes it is difficult to distinguish between texture and noise. But it is also important that the window size is small enough to avoid much deformation within the window. The optimal window size varies from glacier to glacier depending on glacier characteristics like visual contrast and the amount of deformation within the window.

\section{STUDY AREA AND DATA}

The present study area is the Fisher glacier which lies in the Amery Ice shelf system (Figure 1) in Antarctica. It is a prominent western tributary to the Lambert glacier which is about $190 \mathrm{~km}$ long, flowing east past the north sides of Mount Menzies and Mount Rubin and joining the main stream of the Lambert Glacier just east of Mount Stinear. The total area of the extracted glacier in this study is $6525 \mathrm{~km}^{2}$. The estimation of velocity of a glacier through feature tracking needs unique selection of data. The data selected for this study is the Landsat 8 data. The band used for feature tracking is the panchromatic band due to its high resolution of $15 \mathrm{~m}$ while the other bands have a coarser resolution of $30 \mathrm{~m}$.

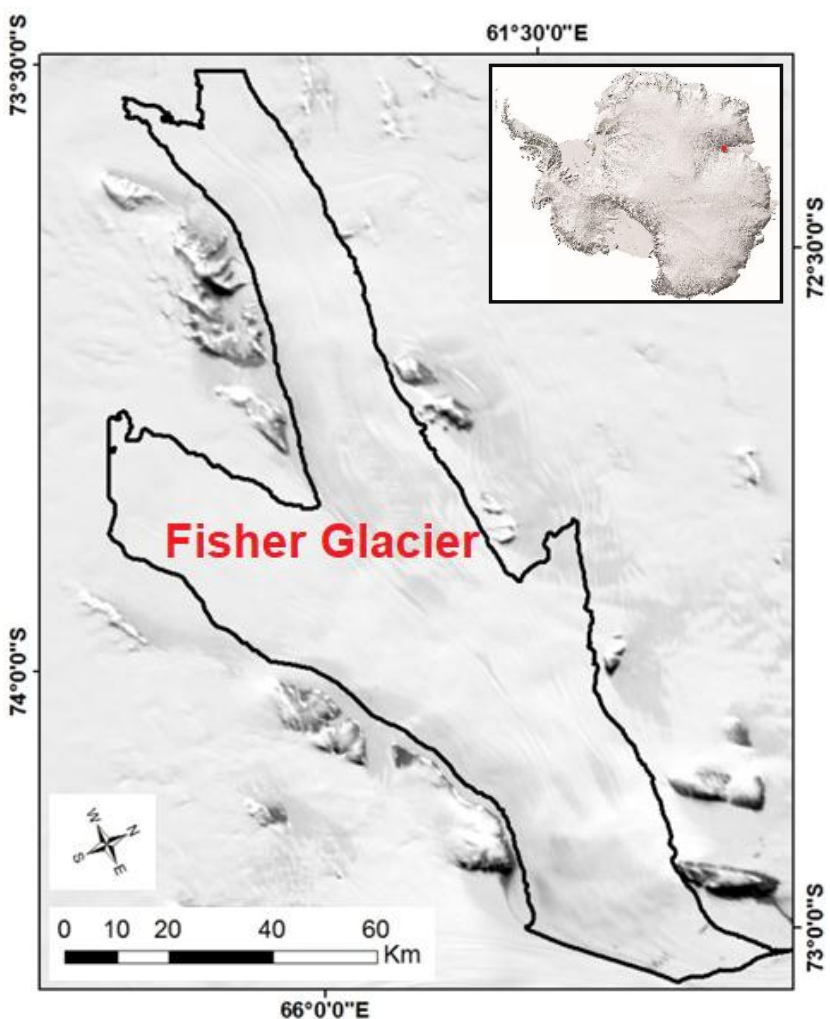

Figure 1: Geographical location of the study area.

\section{METHODOLOGY}

Feature tracking is based on a cross-correlation algorithm that seeks offsets of the maximal correlation windows on repeated satellite images. Co-registration is the pixel by pixel matching and correlation is the degree of matching in image 1 (Master) and image 2 (Slave). The cross-correlation is given by the equation:

$$
C C(u, v)=\frac{\sum \mathrm{x}, \mathrm{y}(\mathrm{f}(\mathrm{x}, \mathrm{y})-\overline{\mathrm{f}})(\mathrm{g}(\mathrm{x}+\mathrm{u}, \mathrm{y}+\mathrm{v})-\overline{\mathrm{g}})}{\sqrt{\sum \mathrm{x}, \mathrm{y}(\mathrm{f}(\mathrm{x}, \mathrm{y})-\overline{\mathrm{f}})^{2} \sum \mathrm{x}, \mathrm{y}(\mathrm{g}(\mathrm{x}+\mathrm{u}, \mathrm{y}+\mathrm{v})-\overline{\mathrm{g}})^{2}}} .
$$

In eq. (1), $f(x, y)$ and $g(x, y)$ are the pixel values in window $Q$ and $\mathrm{Q}^{\prime}$ of image 1 and image 2. $u$ and $v$ are the offsets between $\mathrm{Q}$ and $\mathrm{Q}^{\prime}, \overline{\mathrm{f}}$ and $\overline{\mathrm{g}}(\mathrm{u}, \mathrm{v})$ are the average pixel values of $\mathrm{Q}$ and $\mathrm{Q}^{\prime}$. The correlation window should be large enough to accommodate largest possible displacement (Debella-Gilo and Kääb, 2011).

The function "Correlation" correlates two images and provides a map of the relative displacements.

Pre-event Image: This image is considered as the reference or master. Post-event Image: The slave image to check the displacement. The correlation result provides a displacement field using the convention eastward and northward positive. This displacement field is the horizontal ground displacement that is added to the pre-event image to generate the post-event

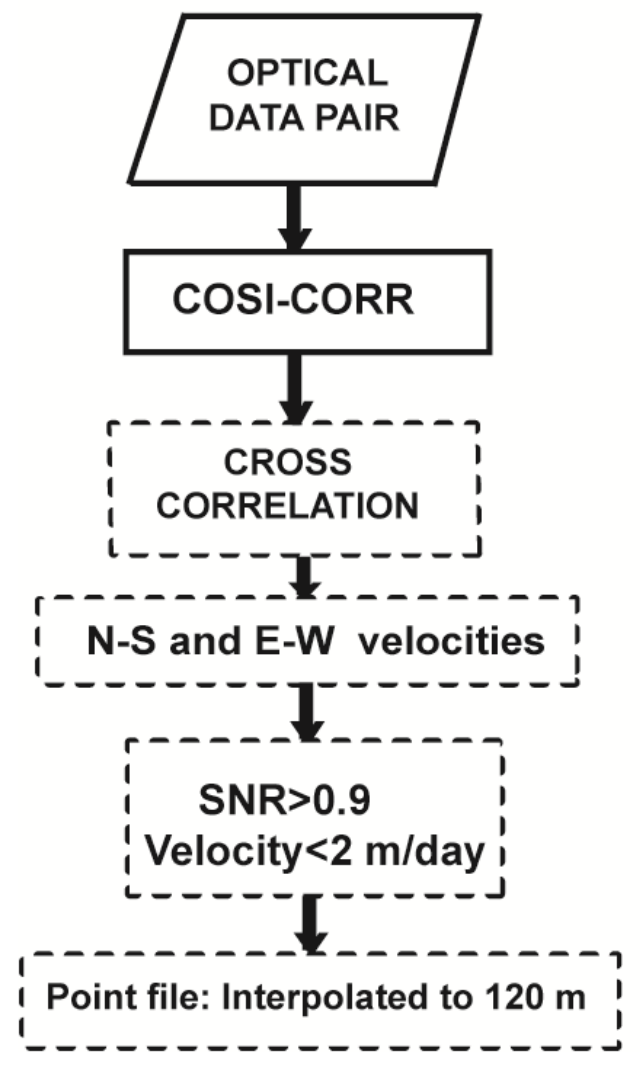

image.

Figure 2: Methodology flowchart.

The correlation file is generated using the panchromatic image pair. Both images need to be georeferenced with the same projection and resolution, the georeferencing is accounted for, and only the geographic overlapping part is correlated. Otherwise, the correlation is pixel based. Currently two correlators are available, which are frequential and statistical. The frequential correlator is Fourier based and is more accurate than the statistical one. The output is in HDR format, so each layer of north-south $(\mathrm{N}-\mathrm{S})$ displacement and east-west $(\mathrm{E}-\mathrm{W})$ displacement needs to be exported separately to get the velocity file. The resolution is determined by the step size which was chosen as 8 . 
The resultant velocity is calculated using the Band Math tool in ENVI. Thus, the result generated is the resultant velocity of E$\mathrm{W}$ and $\mathrm{N}-\mathrm{S}$ direction. The resultant velocity is the square root of the sum of squares of the velocity in each direction. Noise is removed using the Signal-to-Noise ratio (SNR) layer generated in the correlation file. After which using Arc Map the noise values are removed from resultant velocity file using the SNR. The condition adopted here is that SNR should be greater than 0.9 . The velocity was filtered for the values less than 2 mday $^{-1}$, since 2 mday $^{-1}$ is the maximum velocity achieved by the Fisher Glacier. The images were interpolated to get the velocity maps. The resultant map generated has a resolution of $120 \mathrm{~m}$.

\section{RESULTS AND DISCUSSION}

Our results indicate the maximum velocity is estimated as follows: $630.2 \mathrm{myr}^{-1}$ for the year 2013 and $645.5 \mathrm{myr}^{-1}$ for 2014 , and $626.9 \mathrm{myr}^{-1}$ for 2015 which is reduced to $597.4 \mathrm{myr}^{-1}$ in 2016 and increased again to $662 \mathrm{myr}^{-1}$ in 2017. The annual maximum velocity varies from 600 to $650 \mathrm{myr}-1$ where the glacier meets the Amery ice shelf. The mean velocity was 120.2 $\mathrm{myr}^{-1}$ for the year 2013 while in 2014 it increased to $122 \mathrm{myr}^{-1}$ and again subdued to $120.3 \mathrm{myr}^{-1}$ in the year 2015. The year 2016 saw a reduction in the average velocity which was around $112.4 \mathrm{ma}^{-1}$ and there was a stark increase in the year 2017 to $129.8 \mathrm{myr}^{-1}$. The seasonal variations in the year 2013-2014 was found to be $1.8 \mathrm{myr}^{-1}$ while in the next year 2014-2015 it was found to be $1.7 \mathrm{myr}^{-1}$. In the year 2015-2016, there was a dip in the variation by $7.9 \mathrm{myr}-1$ and 2016- 2017 projected a rise to $17.4 \mathrm{myr}^{-1}$. The bias in the year 2013 was $0.7 \mathrm{myr}^{-1}$ followed by $-1.6 \mathrm{ma}^{-1}$ in 2014 . The bias for year 2015, 2016 and 2017 was $0.64,8.54$ and $-8.86 \mathrm{myr}^{-1}$, respectively.

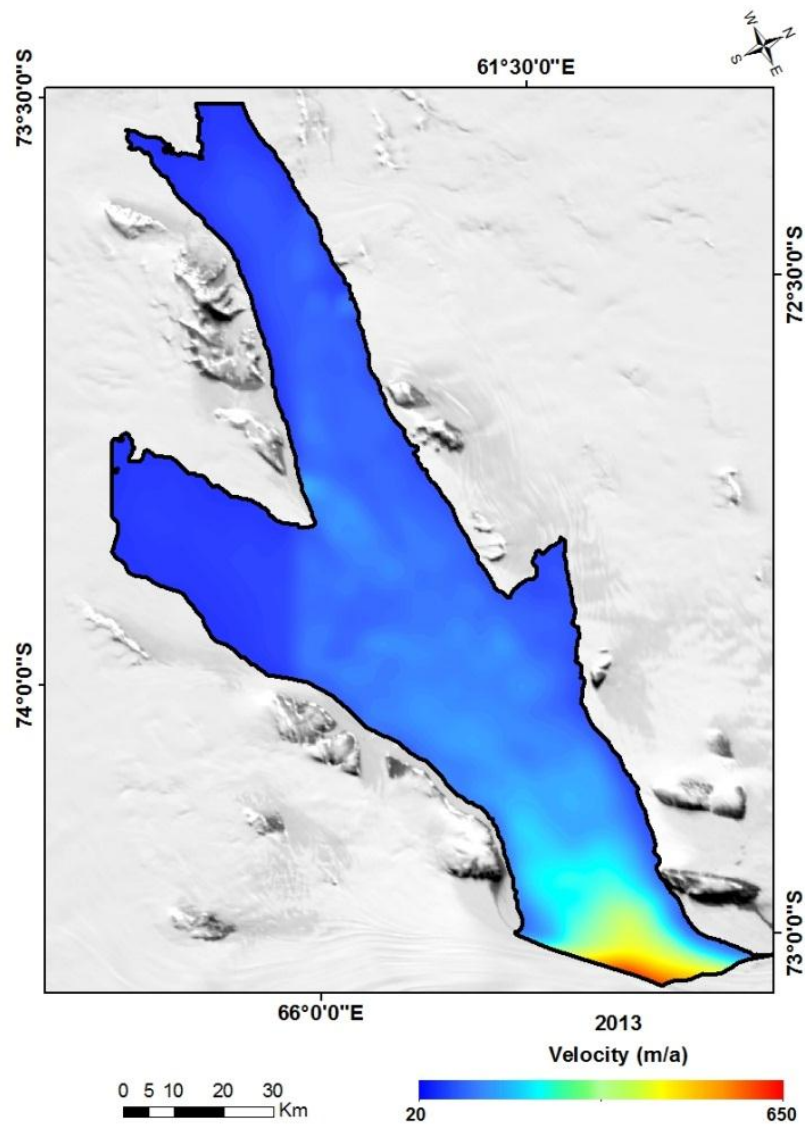

Figure 3: Estimated velocity of Fisher glacier in 2013.

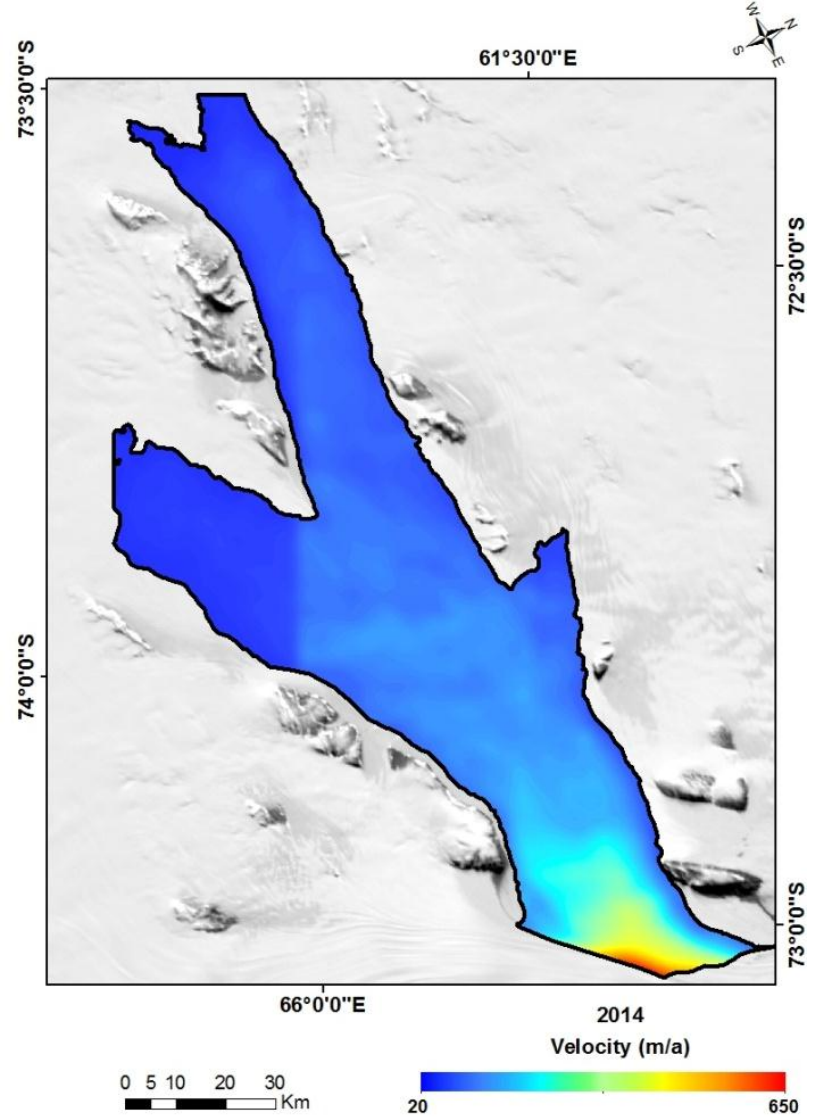

Figure 4: Estimated velocity of Fisher glacier in 2014.

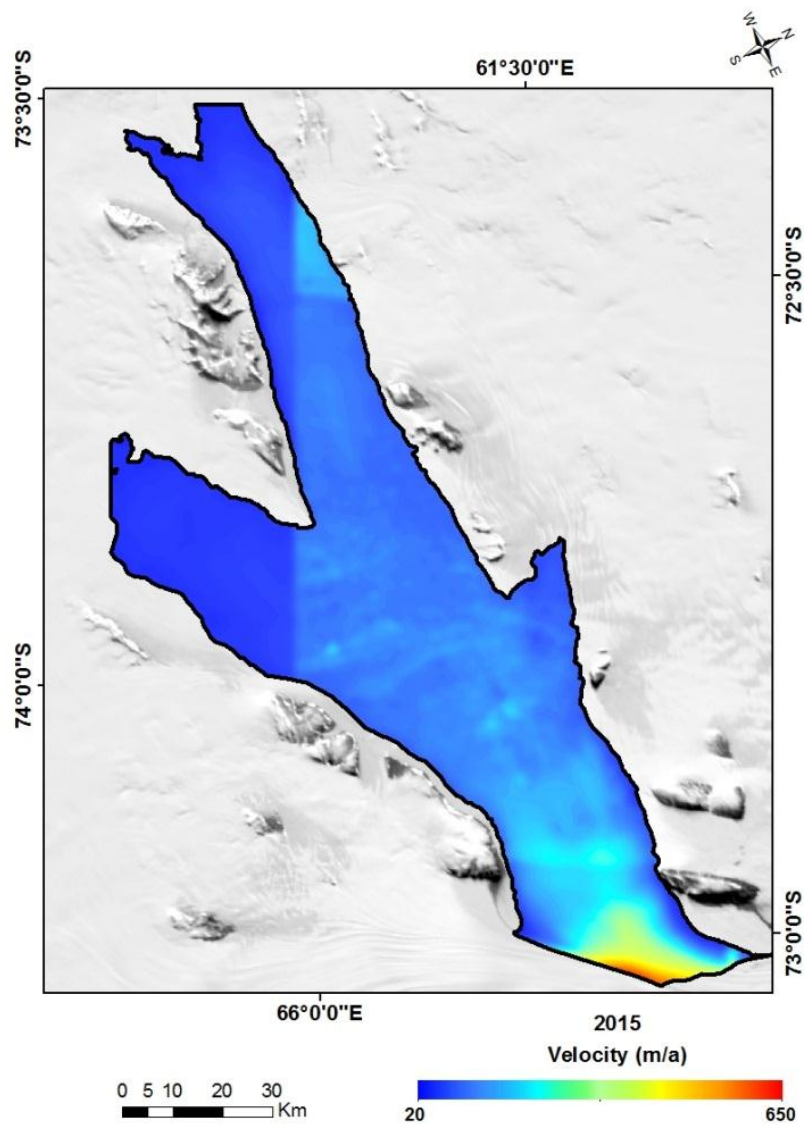

Figure 5: Estimated velocity of Fisher glacier in 2015. 


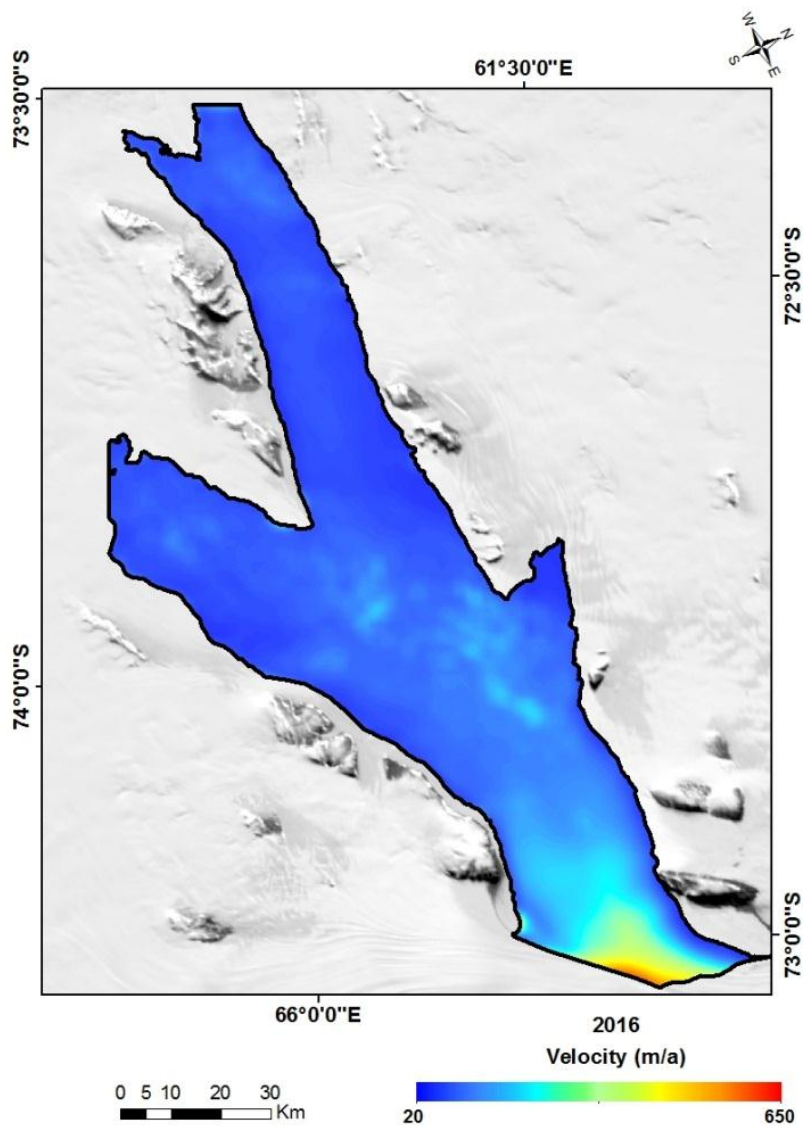

Figure 6: Estimated velocity of Fisher glacier in 2016.

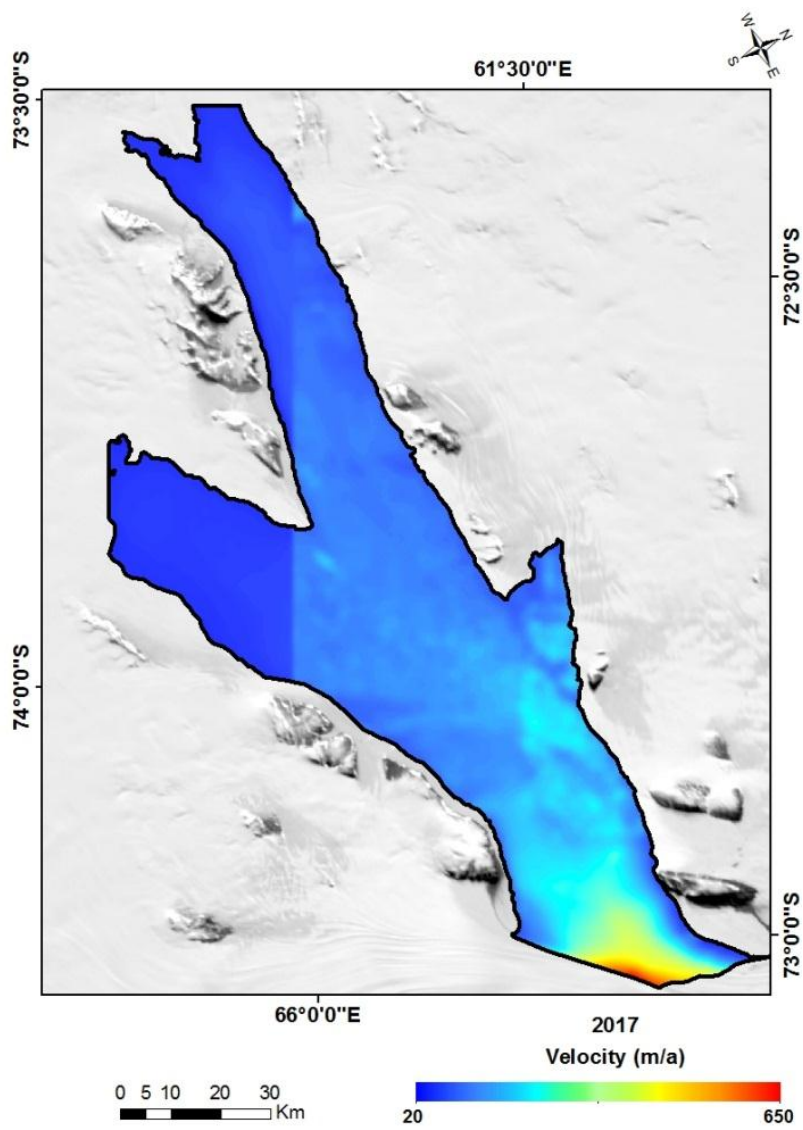

Figure 7: Estimated velocity of Fisher glacier in 2017.

\section{CONCLUSION}

The Fisher glacier velocity was estimated using the method of cross correlation algorithm, which is widely used for optical satellite images. The velocity is a major factor to determine climate change. The velocity was calculated using Panchromatic band (band 8) from Landsat-8 OLI. It was observed that the velocity of Fisher glacier has not varied much. The average velocity of the glacier remained almost the same indicating that no major changes have occurred.

\section{ACKNOWLEDGEMENTS}

We also acknowledge Dr. M. Ravichandran, Director, ESSONCAOR, for his encouragement and motivation for this research. The entire experiment, validation, manuscript preparation, and editing of the manuscript was conducted at the ESSO-NCAOR. The lead author (S.D.J) has recently moved to the SIOS, Longyearbyen, Norway.

\section{REFERENCES}

Debella-gilo, M., and Kääb, A., 2011. Locally adaptive template sizes for matching repeat images of earth surface mass movements ISPRS J. of Photogr.and Rem. Sens., 69, pp. 10-28

Dehecq, A., Gourmelen, N., Trouvé, E., Dehecq, A., Gourmelen, N., and Trouvé, E., 2016. Deriving large-scale glacier velocities from a complete satellite archive: Application to the Pamir-Karakoram-Himalaya, Rem. Sen. Environ., 162(1), pp. 55-66.

Lanari, R., Casu, F., Manzo, M., Zeni G., Berardino, P., Manunta, M., \& Pepe A., 2007. An Overview of the Small BAseline Subset Algorithm: A DInSAR Technique for Surface Deformation Analysis, Pure Appl. Geophysics, 164, 637-661.

Jawak, S.D., Kumar, S., Luis, A.J., Bartanwala, M., Tummala, S., Pandey, A.C, 2018 Evaluation of Geospatial Tools for Generating Accurate Glacier Velocity Maps from Optical Remote Sensing Data. Proceedings 2018, 2, 341.

Jawak, S.D., Pandit, P., Luis, A.J., Malik, K., Sinha, V. S.P., 2017. Derivation of velocity of the Potsdam Glacier, east Antarctica using SAR interferometry, Abstract Id: 94, 38th Asian Conference on Remote Sensing (ACRS 2017), 23-27 October 2017, Delhi, India.

R.M. Goldstein, H. Engelhardt, B. Kamb \& R.M. Frolich, 1993. Satellite radar interferometry for monitoring ice sheet motion: Application to an antarctic ice stream, Science, 262, pp. 15251530

Heid, T. \& Kääb, A., 2012. Evaluation of existing image matching methods for deriving glacier surface displacements globally from optical satellite imagery, Rem. Sens. Environ., 118 , pp. 339-355

T. Strozzi, A. Luckman, T. Murray, U. Wegmuller and C. L. Werner, Glacier motion estimation using SAR offset-tracking procedures, 2002. IEEE Transa. on Geosci. and Rem. Sens., 40(11), pp. 2384-2391.

C. Scott Watson and Duncan Quincey, 2015. Geomorphological Techniques, Chap. 3, Sec. 4.5, British Society for Geomorphology, pp 1-13. 
The International Archives of the Photogrammetry, Remote Sensing and Spatial Information Sciences, Volume XLII-5, 2018

ISPRS TC V Mid-term Symposium "Geospatial Technology - Pixel to People", 20-23 November 2018, Dehradun, India

Goldstein, R. M., Engelhardt, H., Kamb, B., \& Frolich, R. M., 1992. Satellite. Radar Interferometry for Monitoring lce-sheet Motion: Application to an Antarctic INI Stream Richard., Science, 262(5139), pp. 1525-1530.

Pandit, P. H., Jawak, S.D., Luis, A.J, 2018. Estimation of Velocity of the Polar Record Glacier, Antarctica Using Synthetic Aperture Radar (SAR). Proceedings 2018, 2, 332.

Scambos, T.A., M.J. Dutkiewicz, J.C. Wilson and R.A. Bindschadler, 1992. Application of image cross-correlation to the measurement of glacier velocity using satellite image data, Rem. Sens. Environ.,42 (3), 177-186. 